\title{
On the selection of the functional unit in LCA of structural concrete
}

\author{
Snežana Marinković ${ }^{1}$ (D)
}

Received: 9 June 2017 / Accepted: 19 July 2017 / Published online: 21 August 2017

(C) Springer-Verlag GmbH Germany 2017

A recently published article by Panesar et al. (2017) presents an analysis of the impact of the selection of functional unit (FU) on the life cycle assessment of green concretes. The authors correctly emphasize that, despite the multifunctional nature of every concrete structure, many previously performed LCA studies were based on a 'simple' FU, most commonly equal to the unit volume of concrete. For that reason, the authors investigated the influence of six different FUs (which included volume, compressive strength, durability of concrete, binder intensity and a combination of these) on several impact categories.

However, some aspects of this work in my opinion deserve commentary for the sake of scientific fairness and correctness.

Firstly, in the part of the article where previous work was analysed, the comment made on the work of Marinković et al. (2010) on comparative LCA of natural and recycled aggregate concrete is not correct. In this work, all compared concrete mixes were designed to have the same 28-day compressive strength and workability to ensure the same function regarding the strength of a concrete element. To provide for similar durability performance, the analysis was limited to a type of concrete structure for which low-aggressive exposure conditions apply, i.e. with no risk of reinforcement corrosion (such as indoor low air humidity environments of residential and office buildings). The same function was obtained with the same volume (equal to $1 \mathrm{~m}^{3}$ of concrete) but with different mix designs. So, the comparison of the environmental impacts

Responsible editor: Omer Tatari

Snežana Marinković

sneska@imk.grf.bg.ac.rs

1 Faculty of Civil Engineering, University of Belgrade, Bulevar kralja Aleksandra 73, Belgrade 11000, Serbia of the different concrete mixes was made on the basis of a functional equivalency, contrary to the authors' statement in the article.

Panesar et al. (2017) analysed four different concretes with an indication that these specific design mixes are used by the Ministry of Transportation of Ontario in transportation infrastructure. The assessment was performed without specifying the application of concrete-on the 'material' level, but from the context of the article it can be concluded that these mixes are intended for structural applications. In my opinion, the function of the concrete is the function of the structure made of it, and it does not exist independently of the structure in which the concrete is applied.

If rationales and methodology in (Panesar et al. 2017) are applied to any type of concrete structure, following remarks regarding the FU calculation in this work can be put forward:

FUs are not in fact units, but rather measures of the functional performance obtained as ratios of chosen properties of different concrete mixes (they are dimensionless). Final impacts (LCIAresult) of different concrete mixes are obtained by multiplying the 'raw' impacts per unit volume

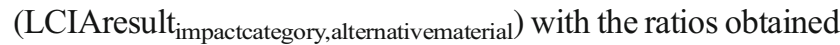
in such a manner (FU). They are also normalized to the impacts of the base material (LCIAresult impactcategory,basematerial), according to Eq. (1):

LCIAresult $_{i, j}=\frac{\text { LCIAresult }_{\text {impactcategory }}, \text { alternativematerial }_{j}}{\text { LCIAresult }_{\text {impactcategory }}, \text {, basematerial }} F U_{j}(1)$

where the base material is conventional cement concrete, and the alternative material is a green concrete (part of cement is replaced with slag or/and silica fume is added).

Calculation of the functional unit $\mathrm{FU}_{2}$ which includes concrete compressive strength was performed by using Eq. (2): 
$\mathrm{FU}_{2}=\frac{\text { compressive_strength }(\mathrm{MPa})_{\text {base_material }}}{\text { compressive_strength }(\mathrm{MPa})_{\text {alternative_material }}}$

On the structural level, Eqs. (1-2) imply that the volume of a structural element is inversely proportional to the compressive strength of concrete. Regarding only the strength of the structural element, this is true only for some stress states, while for some, very common stress states (flexure with or without axial loading) this is not true. For instance, a $20 \%$ higher compressive strength does not necessarily mean $20 \%$ less volume of concrete. This kind of relationship must be assessed on a case-by-case basis.

Calculation of the functional unit $\mathrm{FU}_{3}$ which includes concrete durability performance, specifically chloride attack, was performed using Eq. (3):

$\mathrm{FU}_{3}=\frac{R C P T(\mathrm{C})_{\text {alternative_material }}}{R C P T(\mathrm{C})_{\text {base_material }}}$

where $\mathrm{RCPT}(\mathrm{C})$ is a charge passed through the concrete (Coulombs) determined by the rapid chloride permeability test in accordance with the standard ASTM C1202 (ASTM International 2012) and represents a measure of the chloride permeability of concrete.

On the structural level, Eqs. (1) and (3) imply that the chloride permeability of the concrete is directly proportional to the whole volume of a structural element, regardless of the type of the deterioration mechanism. When talking about chloride attack, two basic deterioration mechanisms of concrete are distinguished: chloride induced corrosion of reinforcement and salt-frost induced surface scaling.

For the chloride-induced corrosion of reinforcement, there are well developed and generally accepted prediction models. According to $f i b$ Model Code for Service Life Design (fib Task Group 5.6 2006), the limit state equation that describes this deterioration mechanism of concrete is as follows:

$a_{c}=e^{-1}\left(1-\frac{\mathrm{C}_{c r i t}-\mathrm{C}_{0}}{\mathrm{C}_{s}}\right) \cdot 2 \cdot \sqrt{k_{e} \cdot \mathrm{D}_{\mathrm{RCM}, 0} \cdot k_{t} \cdot\left(\frac{t_{0}}{t}\right)^{a} \cdot t}+\Delta x$

where

$a_{c}$ depth of the concrete cover-distance between the outer layer of the reinforcement and edge of the concrete section [mm].

$\mathrm{C}_{\text {crit }}$ critical chloride content [wt-\%/c].

$\mathrm{C}_{0}$ initial chloride content of the concrete [wt-\%/c].

$\mathrm{C}_{s}$ chloride content at a depth $\Delta x$ and a certain point of time $t[\mathrm{wt}-\% / \mathrm{c}]$.

$k_{e}$ environmental transfer variable [-].

$k_{t}$ transfer parameter [-].

$\mathrm{D}_{\mathrm{RCM}, 0}$ chloride migration coefficient $\left[\mathrm{m}^{2} / \mathrm{s}\right]$ determined on the basis of the measured depth of chloride ion penetration according to NT Build 492 (1999). $t_{0}$ reference point of time, $t_{0}=0.0767$ years $\left(t_{0}=28\right.$ days $)$. $a$ ageing exponent $[-]$.

$t$ time [years].

$\Delta x$ depth of the convection zone (concrete layer, up to which the process of chloride penetration differs from Fick's 2nd law of diffusion) [mm].

erf error function.

Both $\mathrm{RCPT}(\mathrm{C})$ and $\mathrm{D}_{\mathrm{RCM}, 0}$, although obtained by different tests, represent the measure of concrete's resistance to chloride ingress, and according to Shahroodi (2010), there is practically linear correlation between these two parameters. So it seems like a fair assumption that the basic functional relationship given by Eq. (4) is the same no matter which parameter of the concrete's chloride permeability is used.

The chloride permeability of concrete affects only the depth of the concrete cover because depassivation of reinforcement starts when the critical chloride content is reached at the reinforcement level. According to Eq. (4), the required depth of the concrete cover is proportional to the square root of the chloride migration coefficient (or the charge passed), if all other parameters are the same. This means that if the chloride migration coefficient is increased for instance three times, the required depth of the concrete cover should be increased by $\sqrt{3}=1.73$ times.

More importantly, being several centimetres thick usually, concrete cover makes for only a small part of the volume of the whole concrete element. Exact participation of the concrete cover in the whole volume depends on the type of the structural element, whether it is a girder, slab, wall or column. If the required depth of the concrete cover is increased for instance 1.73 times, the required increase of the whole volume is much smaller and depends mostly on the type of structural element. So, in no case does the relationship implied by Eqs. (1) and (3) exist on the structural level - these equations considerably overestimate the influence of chloride permeability, drastically decrease the 'functional unit' and consequently drastically decrease all impacts of the concrete structure. For instance (Fig. 3 in Panesar et al. (2017)), when FUs, which include the chloride permeability effect $\left(\mathrm{FU}_{3}, \mathrm{FU}_{5}\right.$ and $\left.\mathrm{FU}_{6}\right)$ are applied, all calculated impacts of the concrete with silica fume and slag are approximately ten times smaller compared with the impacts of the conventional concrete. The impacts of the concretes with partial replacement of cement with slag are approximately three times smaller compared with the impacts of the conventional concrete. In my opinion, these results are not valid for any type of the concrete structure, for the reasons mentioned above.

Regarding the salt-frost induced surface scaling mechanism, to the best of my knowledge, there are no generally accepted prediction models at the moment. But without knowing the adequate relationship, this mechanism will also affect only the depth of the concrete cover of the structural element 
Table 1 Calculated FUs by the author of the letter to the editor

\begin{tabular}{llll}
\hline & GU-25SL & GUL-25SL & GU-8SF-25SL \\
\hline $\mathrm{FU}_{1}$ & 1 & 1 & 1 \\
$\mathrm{FU}_{2}$ & 1.35 & 1.40 & 0.86 \\
$\mathrm{FU}_{3}$ & 0.67 & 0.62 & 0.13 \\
$\mathrm{FU}_{4}$ & 1.11 & 1.15 & 0.80 \\
$\mathrm{FU}_{5}$ & 0.90 & 0.86 & 0.11 \\
$\mathrm{FU}_{6}$ & 0.74 & 0.71 & 0.11 \\
\hline
\end{tabular}

and not its entire volume. Therefore, similar reasoning can be applied in this case.

Besides, applying the equations designated as 2-6 in Panesar et al. (2017) on the data reported in Table 2 of this article, the figures in Table 1 are obtained which differ from the figures reported in Table 7 in the article, except for the GU-8SF-25SL concrete. Since this is a very simple calculation, but, on the other hand, is of essential importance for the article, I encourage the authors to explain their calculation or to revise Table 7 and consequently all LCIA results.

In general, the complete functional equivalency in comparative LCAs should include strength, serviceability and durability performance of concrete structural elements. This is a complex task which is hardly possible if the specific application of the analysed concrete structure is not determined, i.e. the strength, serviceability and durability requirements should be an input. One example of defining a functional unit which takes into account all aspects of the structural performance is given in Dobbelaere et al. (2016).

\section{References}

ASTM International (2012) Standard test method for electrical indication of concrete's ability to resist chloride ion penetration. ASTMC120212. ASTM International, West Conshohocken

Dobbelaere G, de Brito J, Evangelista L (2016) Definition of an equivalent functional unit for structural concrete incorporating recycled aggregates. Eng Struct 122:196-208

Marinkovic S, Radonjanin V, Malesev M, Ignjatovic I (2010) Comparative environmental assessment of natural and recycled aggregate concrete. Waste Manag 30:2255-2264

NT Build 492 (1999) Concrete, mortar and cement-based repair materials: chloride migration coefficient from non-Staedy-state migration experiments. Nordtest, Finland

Panesar DK, Seto KE, Churchill CJ (2017) Impact of the selection of functional unit on the life cycle assessment of green concrete. Int J Life Cycle Assess. doi:10.1007/s11367-017-1284-0

Shahroodi A (2010) Development of test methods for assessment of concrete durability for use in performance-based specifications. Master Thesis. Department of Civil Engineering, University of Toronto https://tspace.library.utoronto.ca/handle/1807/25796 retrieved on March $9^{\text {th }} 2017$

fib Task Group 5.6 (2006) Model code for service life design. International Federation for Structural Concrete (fib), Lausanne 